\title{
BOUNDEDNESS FROM BELOW OF COMPOSITION OPERATORS ON $\alpha$-LOGARITHMIC BLOCH SPACES
}

\section{XiaOsong LiU And SONGXIAO Li}

Abstract. In this paper, we characterize the boundedness from below of composition operator on $\alpha$-logarithmic Bloch spaces.

Mathematics subject classification (2010): 47B33, 30H05.

Keywords and phrases: Composition operator, $\alpha$-logarithmic Bloch space, bounded below.

\section{REFERENCES}

[1] L. Brown And A. ShiElds, Multipliers and cyclic vectors in the Bloch space, Michigan Math. J., 38 (1991), 141-146.

[2] H. CHEN, Boundness from below of composition operators on the Bloch spaces, Sci. China Ser. A, 46 (2003), 838-846.

[3] H. CHEN AND P. GAUTHIER, Boundness from below of composition operators on the $\alpha$-Bloch spaces, Canad. Math. Bull., 51 (2008), 195-204.

[4] H. CHEN AND M. ZHANG, Boundness from below of multiplication operators between $\alpha$-Bloch spaces, Canad. Math. Bull., 53 (2010), 23-36.

[5] C. Cowen And B. MacCluer, Composition Operators on Spaces of Analytic Functions, Studies in Advanced Math., CRC Press, Boca Raton, 1995.

[6] P. Ghatage, J. YAn And D. Zheng, Composition operators with close range on the Bloch spaces, Proc. Amer. Math. Soc., 129 (2000), 2039-2044.

[7] P. Ghatage, D. Zheng And N. Zorboska, Sampling sets and close range composition operators on the Bloch spaces, Proc. Amer. Math. Soc., 129 (2004), 1371-1377.

[8] S. YE, Cyclic Vectors of Analytic Function Spaces and Related Operator Theory, PhD Dissertation, Shantou Unversity, 2010.

[9] S. YE, A weighted composition operator on the logarithmic Bloch space, Bull. Korean Math. Soc., 47 (2010), 527-540.

[10] R. YonedA, The composition operators on weighted Bloch space, Arch. Math. (Basel), 63 (2002), 310-317.

[11] K. ZHU, Operator Theory in Function Spaces, Marcel Dekker, New York, 1990. 